\title{
Biblioteca digital de árvores de rua de Curitiba: método e produção
}

\author{
Trees in Curitiba streets: methodology and production of a digital library
}

- Profa. Dra. Gisele Pinna Braga

Universidade Positivo, Brasil

gbraga@up.edu.br

Alex Franz Wilezelek

Universidade Positivo, Brasil

alexwilezelek@gmail.com

\author{
Jahsun Daher Golding \\ Universidade Positivo, Brasil \\ jah.dg@hotmail.com \\ - Oliver Uszkurat \\ Universidade Positivo, Brasil \\ oliveruszkurat@gmail.com
}

\begin{abstract}
Digital representation is an important resource for the architect's work in all project stages. The use of appropriate representations facilitates proper interpretation of the project, resulting in more accurate design decisions. This article presents the entire process and the results of a n academic research that developed a digital library that contains 25 species of trees, easily found in Curitiba streets. It also describes the methodology that was built throughout the study, which focuses on a production of representations that do not depend on special talent or personal drawing characteristics. Finally, it shows the produced representations and provides a brief analysis of the results.
\end{abstract}

Keywords: Árvores, Curitiba, Biblioteca Digital

\section{Introdução}

No trabalho do profissional arquiteto, que é intervir no ambiente existente, ele utiliza a representação como principal ferramenta de expressão de suas ideias e propostas.

A representação gráfica digital é uma delas, e requer do profissional o conhecimento de softwares e de tecnologias que agilizem o seu trabalho, uma vez que esse requer produtividade.

No ambiente urbano, as árvores de rua são variadas e apresentam diferentes formas, texturas, cores, volumes e fases.

Hoje em dia, os profissionais do ramo utilizam em seus projetos, em sua maioria, um banco de dados de árvores genéricas, não considerando na representação as especificidades de cada espécie. Por isso, essa representação é feita desconsiderando a espécie em si, mas agrupando características gerais.

Numa situação de projeto, em que há a necessidade de representar uma espécie perene, a representação genérica de uma árvore em fase caduca pode trazer equívocos de decisões de projeto.

Outro fato importante, que mostra a necessidade de uma adequada representação ocorre na cidade de Curitiba, onde o apelo às necessidades de conservação e adequação do meio ambiente são rigorosamente praticadas para que espécies coexistam de maneira simbiótica.

O decreto municipal 1181, de 2009, por exemplo, declarou imune de corte 21 árvores contidas no documento, e em segunda instância este número foi aumentado para 43 em sua revogação de 2014.

Sendo assim, estas leis relacionadas ao assunto intervém de forma significativa nas escolhas e determinações de espécies, de modo que sejam respeitados, além de seu valor social, também o seu valor histórico.

Analisando a importância de caracterizar corretamente as árvores a serem implantadas em projetos de arborização urbana na cidade de Curitiba e representadas quando da produção de um projeto arquitetônico, o objetivo deste estudo é, além de criar bibliotecas digitais com as representações específicas de árvores de rua existentes na cidade, desenvolver uma metodologia para criação de seus objetos gráficos. As bibliotecas produzidas podem ser utilizadas por profissionais e estudantes do ramo de arquitetura ou afins na representação de seus projetos, e a metodologia desenvolvida pode ser aplicada para outras espécies de árvores, na produção de novos objetos gráficos.

\section{Metodologia}

O método de criação do acervo digital partiu da premissa de se criar um processo racional que pudesse ser reproduzido por qualquer pessoa com domínio das ferramentas utilizadas. Tal decisão coincide com a preocupação de desenvolver um método que possibilitasse resultados independentes de talentos pessoais de representação e que, ao mesmo tempo 
não prejudicasse a fidelidade de representação das espécies.

O desenvolvimento tomou como base 24 árvores de rua relacionadas no livro ÁRVORES DE CURITIBA (p.70, 2004), que apresenta uma gama de 55 espécies existentes na paisagem curitibana. As espécies deste grupo apresentaram maior relevância para este trabalho, uma vez que estão localizadas em espaços de maior interferência do trabalho do arquiteto.

Uma espécie apresentada no livro, mas que não está contida na lista de árvores de rua é a Araucária, que além de ser um símbolo local, apresenta características singulares e se destaca em vários locais públicos. Por estes motivos optou-se por sua inclusão na lista de árvores para esse trabalho.

Assim, foram 25 espécies que tiveram as seguintes bibliotecas gráficas desenvolvidas:

- Acervo de imagens fotorrealística;

- Acervo de imagens de caráter de ilustração;

- Biblioteca de pincéis (brushes) para Photoshop;

- Biblioteca de máscaras de silhuetas;

- Biblioteca de blocos de em AutoCAD, com baixo e alto graus de detalhes;

- Bloco único "Árvores de Curitiba" em AutoCAD, com todas as silhuetas das árvores.

\section{Ferramentas utilizadas}

A representação gráfica das árvores dependia, além dos processos, também da escolha dos softwares utilizados. Para o trabalho com arquivos de imagem foi escolhido o Adobe Photoshop, por ser uma ferramenta profissional de edição de imagens. Para o trabalho com objetos vetoriais optouse pelo Adobe Ilustrator, por ser totalmente compatível com o Photoshop; e o AutoCAD, por ser uma ferramenta de desenho em $2 d$ amplamente utilizada por arquitetos. Além desses critérios de escolha, foi levado em conta os programas disponíveis no laboratório de computação gráfica do curso de Arquitetura e Urbanismo da Universidade Positivo, infraestrutura disponível para a realização desta pesquisa.

\section{Itens representados e graus de representação}

Escolheu-se representar espécies vegetais em elevação, dado ao grande uso em projetos e apresentações arquitetônicas. A facilidade de identificação das características únicas de cada espécie, se comparada com a representação das mesmas em planta corroborou tal decisão.

Os graus de detalhamento foram sintetizados em baixo detalhamento - onde vê-se principalmente a silhueta característica da árvore - e alto detalhamento, onde ficam evidentes características mais específicas como angulação dos galhos, ramos e densidade de folhas.

\section{Procedimentos realizados}

Iniciou-se com o levantamento fotográfico das árvores, para preservar a autoria do trabalho, considerando: evitar fundos com vegetação ou construções com muito detalhes; tirar fotos em dia nublado por volta do meio, para evitar grandes contrastes; posicionar-se à distância mínima equivalente à altura da árvore.

Em seguida excluiu-se o fundo no Photoshop e salvouse em .PNG. Importou-se este resultado fotorrealístico no Illustrator para vetorizá-lo nos diferentes níveis de detalhamento, para gerar o "resultado em modo ilustração" e o "resultado silhueta".

Para criação da biblioteca de pinceis (brushes), usou-se o resultado em modo ilustração, que nas características que o Photoshop oferece, é a melhor opção de representação em escalas de cinza. O conjunto de pinceis produzidos foram agrupados e salvos em um arquivo .ABR

Para a criação dos blocos em AutoCAD utilizou-se dois arquivos PNG, previamente produzidos. Vetorizou-se cada um individualmente no Adobe Illustrator, a fim de se obter alto e baixo graus de detalhamento. As linhas foram exportadas em formato DWG.

Para cada espécie, no AutoCAD, utilizou-se a ferramenta "Visibility States" para criação de um bloco único, com possibilidade de alternância de seu grau de detalhe, durante o trabalho de desenho de projeto.

Ainda no AutoCAD produziu-se um bloco que inclui a representação de todas as 25 espécies, com sua representação em baixo grau de detalhe. Tal bloco também foi criado com a ferramenta "Visibility States", possibilitando a inserção de um único bloco no desenho do projeto, e a escolha da espécie sem que seja necessária a troca do bloco.

O processo de produção é ilustrado abaixo:

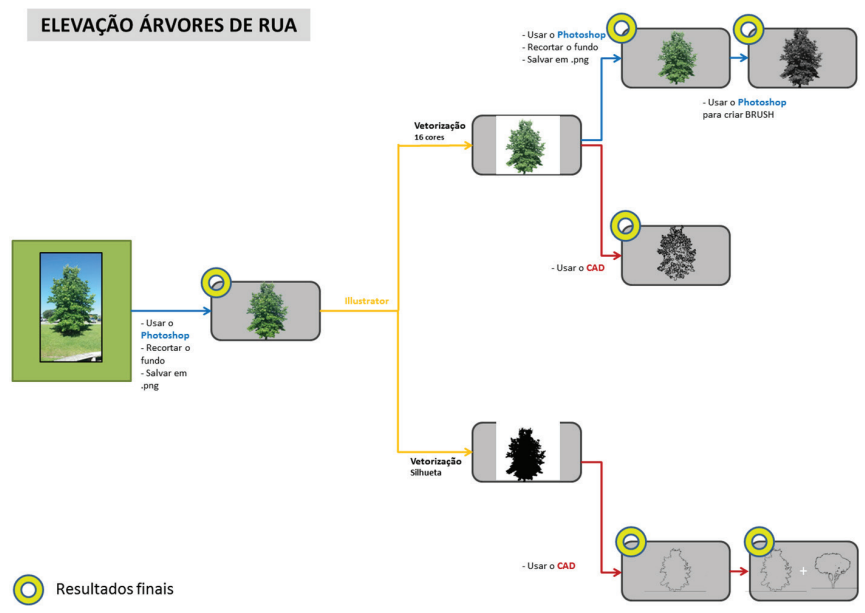

Figura 1: Esquema que ilustra o processo de produção das representações.

\section{Resultados Obtidos}

Os resultados obtidos foram a metodologia de criação das bibliotecas gráficas e o acervo das bibliotecas gráficas para as 25 espécies definidas no estudo. Os mesmos são ilustrados a seguir: 


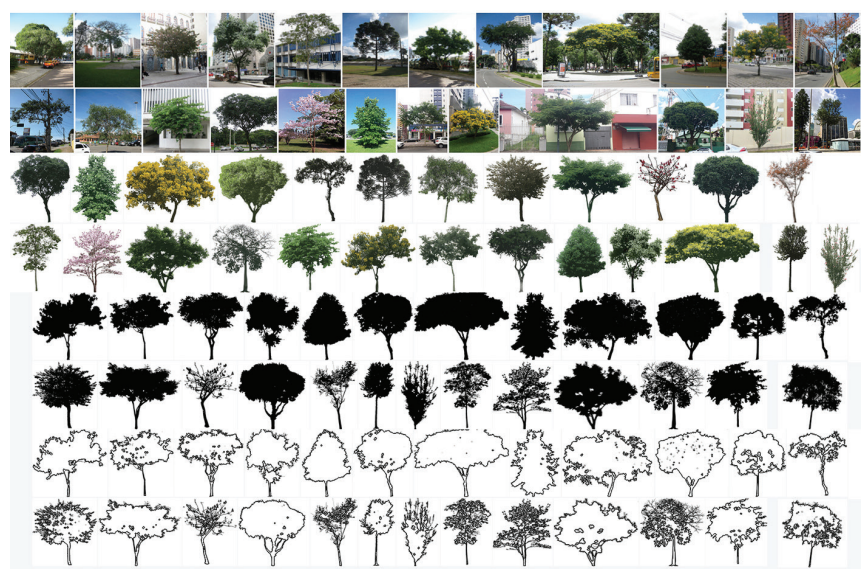

Figura 2: Imagens de representações produzidas. Produção da pesquisa.

\section{Considerações Finais}

O desenvolvimento de um método de representação gráfica digital de espécies vegetais foi realizado. Aplicou-se o método na produção da representação vinte e cinco espécies de rua da Cidade de Curitiba, mostrando que é possível representar distinções peculiares de várias espécies, mesmo em árvores de anatomia muito semelhantes.

O acervo produzido servirá para estudantes e profissionais do ramo de arquitetura para a produção de novos projetos ou para representar os locais nos quais estes estão inseridos. O mesmo será disponibilizado no website que apresenta as atividades do curso de Arquitetura e Urbanismo da Universidade Positivo, no endereço www. up.edu.br/cadernoau.

Os desdobramentos desta pesquisa podem ser vários, como:
- aplicação da metodologia na produção de biblioteca gráfica de espécies de árvores de outras cidades;

- adequação desta metodologia para a produção de bibliotecas gráficas para outros softwares;

- uso do material gráfico na criação de bibliotecas 3D;

- adequação das bibliotecas vetoriais para fabricação digital.

\section{Referências}

CARDOSO, Francisco. Árvores de Curitiba. Editora do Autor, 2004.

REYES, P. E. B. A criação pela imagem no projeto urbano. In: $2^{\circ}$ Sem. Int. Representar Brasil 2013 - as representações na arquitetura, urbanismo e design, 2013, São Paulo. Anais do $2^{\circ}$ Sem. Int. Representar Brasil 2013 - as representações na arquitetura, urbanismo e design. São Paulo: EDUSP, 2013. v. 01. p. 27-41.

SALMASO, J.; VIZIOLI, S. H. T. O uso do modelo físico e digital nos processos de projeto da arquitetura contemporânea. In: 21o. Siicusp - Simpósio Internacional de Iniciação Científica, 2013, São Paulo. CD on line do 21o. Siicusp - Simpósio Internacional de Iniciação Científica, 2013.

CUNHA, Erick Vinícius Silva da. Modelagem gráfica de espécies da Caatinga. In: $2^{\circ}$ Seminário Int. Representar Brasil 2013 - as representações na arquitetura, urbanismo e design, 2013, São Paulo. Anais do $2^{\circ}$ Seminário Int. Representar Brasil 2013 - as representações na arquitetura, urbanismo e design. São Paulo: EDUSP, 2013. v. 01.

OLIVEIRA, Victor Maciel do N.; PARANHOS, Lucas Giordano; ALVAREZ, Ivan André. Levantamento qualitativo de espécies vegetais nos espaços verdes urbanos do centro de Petrolina, PE. Anais da II Jornada de Iniciação Cientifica da Embrapa Semi-Árido, p. 27, 2007. 